\title{
GBEP
}

\section{Gestão municipal e formação: a educação infantil no Estado do Rio de Janeiro}

Sonia Kramer

Maria Fernanda Nunes

\section{Resumo}

Sintetiza resultados de pesquisa realizada sobre gestão e políticas e práticas de formação de profissionais da educação infantil implementadas por redes públicas municipais de educação. Os dados foram obtidos através da aplicação de questionário a todos os municípios do Estado do Rio de Janeiro. O texto aborda: os sistemas de educação no Estado do Rio de Janeiro, sua organização e as áreas incluídas nas Secretarias de Educação; a cobertura do atendimento e da articulação com o ensino fundamental; as políticas de formação dos profissionais de educação infantil, o ingresso e a carreira nas redes municipais; as condições concretas de implementação das políticas quanto aos recursos materiais dos municípios e às agências e atividades culturais disponíveis. infantil.

Palavras-chave: gestão pública; formação de profissionais; educação

\section{Abstract \\ Municipal management and formation: childhood education in the State of Rio de Janeiro \\ The paper synthesizes the results of a research carried through on the management and policies and practices on the formation of professionals of}


childhood education implemented by the municipal public education systems. The data were gathered through the administration of a questionnaire to all the cities of the State of Rio de Janeiro. The text approaches: the systems of education in the State of Rio de Janeiro, its organization and areas included in the Secretariats of Education; its scope and articulation with basic education; the policies in relation to teachers formation, the ingression and the career in the municipal systems; the concrete conditions of policies implementation concerning the material resources of the cities and the available agencies and cultural activities.

Keywords: public administration; teachers formation; childhood education.

\section{Introdução}

Entender a educação de um município como um sistema educacional, nos seus diferentes níveis e dependências administrativas, significa buscar unidade na diversidade, integrar as partes no todo, assegurando um conjunto operante e coerente, mas que também preserve as especificidades. Embora essa definição seja clara e lógica, colocá-la em prática, especialmente em relação à educação das crianças de 0 a 6 anos de idade, não é nem tem sido simples, uma vez que exige gerenciamento em todos os níveis. A história da educação infantil não tem favorecido a inserção, por ser marcada por uma concepção assistencialista e sanitarista para as creches e compensatória e preparatória para as pré-escolas; pela precariedade da profissionalização e de formação dos seus profissionais; pela falta de compreensão da especificidade do trabalho pedagógico para a faixa etária que atende, além de inúmeras questões relacionadas com os espaços físicos, vínculo empregatício (voluntariado, terceirização, entre outros aspectos), convênios, captação e distribuição de verbas.

Buscar a unidade do sistema diante da diversidade, aceitar e conviver com diferenças sem tornar o sistema disperso e/ou excludente, compreender e conceber o espaço educativo, com o envolvimento, discussão e formação dos profissionais que nele atuam, exige do sistema ações políticopedagógicas e administrativas consistentes, objetivas e que tenham continuidade. Tais objetivos exigem recursos financeiros e implicam ações políticas direcionadas, prioritariamente, para a formação dos profissionais que trabalham em creches e pré-escolas, em classes de alfabetização e no próprio ensino fundamental.

Segundo Both (1997), o grande desafio da municipalização é construir um sistema de ensino onde as esferas governamentais (municipal, estadual e federal) atuem de forma integrada, a fim de concretizar uma política pública destinada a todos os cidadãos brasileiros.

Este texto se situa no contexto desta questão e se baseia na pesquisa "Formação de profissionais de educação infantil no Estado do Rio de Janeiro". 
Realizada na PUC-Rio, de 1999 a 2004, investigamos a situação da educação infantil nos municípios do Estado, no que se refere à organização do sistema de ensino, cobertura do atendimento às crianças de 0 a 6 anos, gestão, formação de profissionais; ingresso e carreira, recursos financeiros e materiais, instituições ou agências sociais e culturais existentes nos municípios. Para compreender as políticas de formação de profissionais da educação infantil, procuramos conhecer as histórias das propostas de formação e as histórias de profissionais responsáveis, nas Secretarias Municipais de Educação, pela gestão da educação infantil. Um questionário foi enviado a 91 Secretarias Municipais de Educação. Além desse instrumento, entrevistamos equipes responsáveis pela educação infantil de 11 municípios da Região Metropolitana (que concentram 1.100.000 das 1 500 mil crianças de 0 a 6 anos residentes no Estado do Rio de Janeiro) em 5 entrevistas coletivas (com 57 responsáveis pela educação infantil de diferentes regiões do Estado). O referencial teórico-metodológico se baseou na concepção de linguagem de Bakhtin e na concepção de narrativa de Walter Benjamin. A implementação de propostas de formação e suas práticas educativas e culturais foram analisadas por meio de estudos de caso em monografias de especialização, dissertações de mestrado e teses de doutorado.

Com base nesta pesquisa, abordamos inicialmente neste texto os sistemas de educação no Estado do Rio de Janeiro, em termos de organização e áreas que englobam a secretaria de educação. Em seguida, tratamos da educação infantil com foco na cobertura do atendimento e da articulação com o ensino fundamental. No terceiro momento, analisamos a política de formação dos profissionais de educação infantil, o ingresso e a carreira nas redes municipais. Por último, apresentamos as condições concretas de implementação das políticas, tanto no que diz respeito aos recursos materiais dos municípios quanto às agências e atividades culturais disponíveis. As considerações finais apontam desafios da gestão municipal nestes tempos de debate e luta para que a educação infantil se torne direito de fato de todas as crianças.

\section{Os sistemas de educação do Estado do Rio de Janeiro}

A opção legal de tornar-se um sistema de ensino está alicerçada na construção de uma gestão democrática, num ensino público mais aberto à universalização de acesso e permanência, num salto qualitativo mais amplo do direito à educação (Cury, 2000). Neste item, apresentamos a organização dos sistemas de ensino e dos conselhos municipais de educação, descrevendo também as áreas que as Secretarias Municipais de Educação do Estado do Rio de Janeiro englobam.

Foram consideradas, na pesquisa, as regiões do Estado definidas pelo IBGE, totalizando nove regiões, a saber: Capital, Metropolitana, Noroeste, Norte, Serrana, Baixadas Litorâneas, Médio Paraíba, Litoral Sul Fluminense e Centro-Sul. 


\subsection{Organização dos sistemas de ensino e dos Conselhos Municipais de Educação}

A inserção das creches e pré-escolas no sistema educacional tem-se revelado um dos pontos mais frágeis das políticas municipais para a educação básica, e a incorporação das crianças de seis anos ao ensino fundamental é também um outro ponto que necessita de atenção. Se, por um lado, tal inserção pode significar um ganho para as crianças pelo acréscimo de um ano de escolaridade obrigatória, por outro, a falta de integração entre o administrativo e o pedagógico pode reforçar exclusões. A adequação do ensino fundamental para acolher as crianças enfrenta problemas, a começar pela ampliação das vagas. Constitucionalmente, a obrigatoriedade escolar é de 7 a 14 anos de idade, mas, com as novas configurações deste nível de ensino, deve se ter claro que ela se estendeu às crianças de 6 anos. Portanto, é necessário viabilizar a ampliação, disponibilizando e adequando salas de aula, pessoal docente e infra-estrutura necessária para atender à demanda. Também não podem ser negligenciados fatores pedagógicos que perpassam o acolhimento, com mudanças de concepção do próprio ensino fundamental, incorporação de novos conceitos, alterações no tempo de duração, substituição do sistema seriado por ciclos, reformulações nas avaliações do processo, entre outras, exigindo investimento na formação continuada em serviço dos seus profissionais.

As lacunas na oferta de vagas na rede pública, além de abrirem espaço para o atendimento privado, dão margem à existência de espaços alternativos ou "oficiosos" que, sem critérios de funcionamento e supervisão dos órgãos competentes, põem em risco a qualidade do atendimento à criança.

Dos 91 municípios do Estado do Rio de Janeiro, existentes na época da pesquisa, 54 devolveram o questionário respondido. Destes, 52 já tinham seu próprio sistema de ensino, e um município - Carapebus, na Região Norte Fluminense - optou pela organização do seu sistema integrado ao sistema estadual. O município de Cardoso Moreira, nessa região, não respondeu a este quesito, não sabemos se por desconhecimento do respondente sobre o que é um sistema de ensino. Esta hipótese, se confirmada, permite dizer que a equipe técnica de uma secretaria de educação deve estar atenta para sua responsabilidade em relação à oferta, organização e qualidade do atendimento público e privado daquele município.

O papel de uma secretaria de educação se refere à gestão da rede pública e privada da região, neste caso para orientar o credenciamento e o funcionamento das instituições de educação infantil.

A Assembléia Legislativa do Estado do Rio de Janeiro (Alerj) entendeu a necessidade de criação de uma lei para a organização do seu sistema de ensino estadual. Entretanto, a lei que estabelece as "Diretrizes para a organização do sistema de ensino do Estado do Rio de Janeiro" (Lei no 4.528) foi sancionada, apenas, em março de 2005. Ora, como o questionário foi enviado após o término estabelecido pela LDB, e todos os estabelecimentos de creches e pré-escolas deveriam ter sido credenciados em seus respectivos sistemas de ensino (dezembro de 1999), já se pode perceber o papel pouco 
indutor que o Estado vem desempenhando na formulação e organização das instituições de ensino, tanto públicas quanto privadas. Assim, o município de Carapebus, ao optar pelo seu sistema de ensino vinculado ao sistema estadual, ficou defasado e, quem sabe, prejudicado na composição da educação básica municipal (entendendo as instituições públicas e privadas). Da mesma maneira, sabendo a importância das políticas estaduais na organização municipal, uma vez que muitas regiões carecem de condições físico-financeiras e de recursos humanos, os outros 53 municípios tiveram que se organizar a partir do seu próprio contexto, muitas vezes sem poderem se apropriar das reflexões, estudos e pesquisas disseminadas no Estado.

Na ocasião de discussão do então projeto de lei, a Comissão de Educação da Alerj promoveu audiências públicas com secretários municipais de educação, universidades e organizações não-governamentais. Tendo representado o Fórum Permanente de Educação Infantil do Estado do Rio de Janeiro, nesta reunião, podemos levantar reflexões referentes à referida lei. Como exemplo de tais questionamentos, podemos citar o capítulo II "da composição do sistema", artigo $7^{\circ}$, que estabelece que o sistema de ensino é composto de:

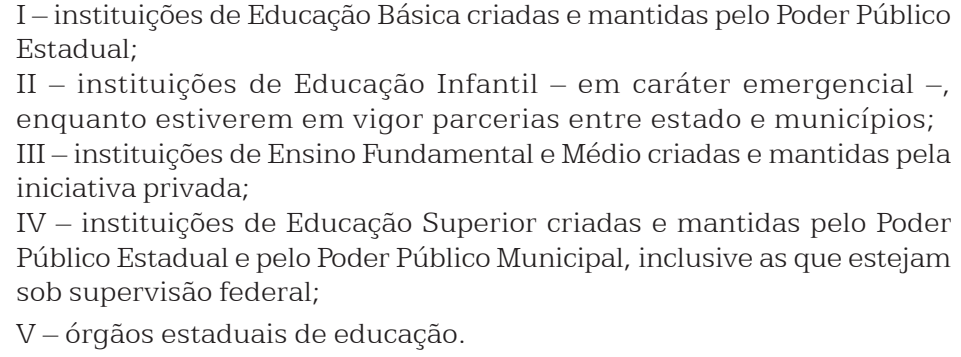

O sistema de ensino "adotou", na lei, a competência para o atendimento educacional, da rede estadual de ensino, e não a organização propriamente dita da educação infantil, do ensino fundamental e médio, formulando que o sistema será composto pelas "Instituições de Educação Infantil", apenas em caráter emergencial. Neste sentido, o grande desafio é construir um sistema de ensino no qual as esferas governamentais (municipal, estadual e federal) atuem de forma integrada, com o objetivo de concretização de uma escola pública de qualidade, coerente e destinada a todos os cidadãos brasileiros.

No que se refere à existência de Conselho Municipal de Educação, constatamos que 49 municípios têm conselhos, 4 estão em processo de organização - Cantagalo e Carmo, na Região Serrana; Guapimirim e Rio Bonito, na Região Metropolitana - e um não tem conselho próprio, Carapebus, uma vez que está articulado ao Conselho Estadual de Educação.

Vale observar que, dos que disseram que têm Conselho Municipal de Educação, 57,1\% possuem um setor específico para a educação infantil e 78\% possuem profissionais específicos para a educação infantil. A especificidade do atendimento em relação à criança de 0 a 6 anos nos induz 
a questionar a competência das equipes que não dispõem de um setor específico para a educação infantil, na formulação de uma política municipal de educação infantil que expresse as orientações referentes ao acompanhamento a estas instituições, além da apropriação dos padrões mínimos necessários para um atendimento de qualidade.

De maneira geral, outras secretarias, além da Secretaria de Educação, prestam serviços educacionais à população infantil. Entre elas se destacam a Secretaria de Saúde, fazendo tratamento e acompanhamento médico e odontológico e organizando programas educativos de prevenção de doenças, e a Secretaria de Assistência/Bem-Estar/Desenvolvimento, organizando e mantendo creches e dando assistência social à criança, ao adolescente e à família. Os serviços de assistência são considerados pelas secretarias, conforme apontado, como atendimento educacional. As respostas ao tipo de atividade desenvolvida por essas secretarias foram bastante diversas: cesta básica, médicos de família, exploração turística, vacinação e prevenção, oficinas de artesanato e atendimento psicológico. É estranho supor que estas ações sejam qualificadas, pelos informantes, como um serviço do tipo educacional. Em geral, como apontado, são programas integrados às creches e pré-escolas, que, em muitos casos, conforme observação, se restringem a este atendimento.

Esse dado é relevante, uma vez que o atendimento em creches e préescolas, desde dezembro de 1999, está vinculado à coordenação da Secretaria de Educação. Assim, a verba da Assistência para esse atendimento deveria, em princípio, ser transferida para a Secretaria de Educação. Entretanto, como observamos nas entrevistas, muitas secretarias vinculadas ao bem-estar social, depois que deixaram de atender às crianças, principalmente às de creche, passaram a dar outro destino para os recursos existentes, possivelmente os citados acima.

As secretarias de Japeri, Belford Roxo, Queimados e Tanguá, para citar os municípios da Região Metropolitana, foram aquelas que não levantaram nenhum tipo de atendimento, quando a elas se perguntou "Que secretarias prestam serviços educacionais à população infantil?" As secretarias da Região Metropolitana concentram alta porcentagem de crianças de 0 a 6 anos residentes, mas, contraditoriamente, têm um baixo índice de cobertura (Nunes, 2005). ${ }^{1}$

\section{2 Áreas que englobam as Secretarias Municipais de Educação}

Quanto às áreas englobadas pela Secretaria de Educação, a maior incidência recai na área de cultura: são 21 Secretarias de Educação e Cultura, seguidas por 19 Secretarias de Educação, Cultura, Esporte e Lazer e 3 Secretarias de Educação, Cultura e Esporte (Gráfico 1). Vale destacar que, em 19 municípios, a Secretaria de Educação não engloba outras áreas de atuação, o que revela maior especificidade de funções e possibilidade de concen-

${ }^{1}$ Sobre este tema, ver a tese de doutorado de Nunes (2005) tração nas questões educacionais. 


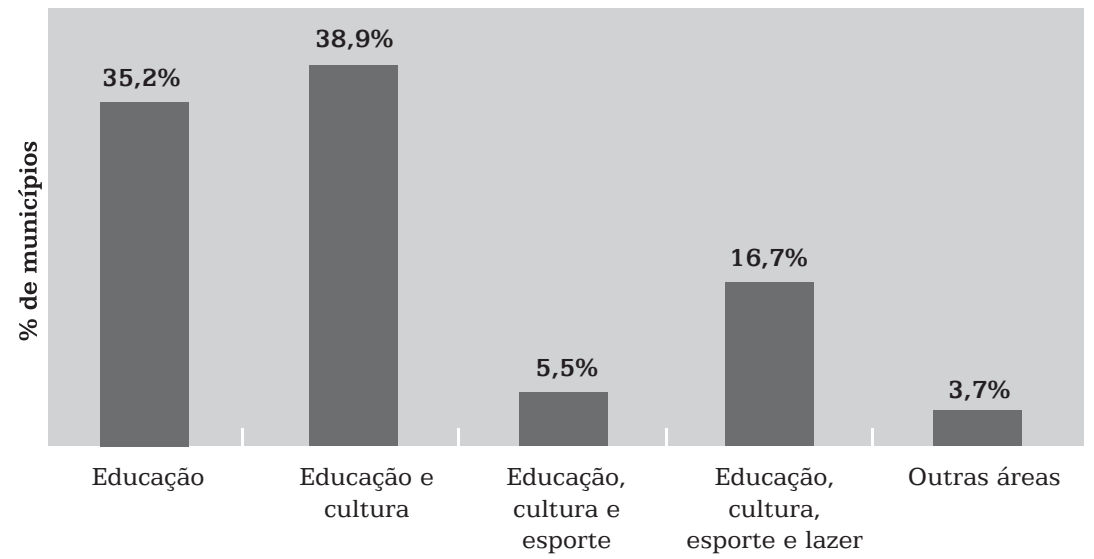

Áreas englobadas pelas secretarias de educação

Gráfico 1 - Distribuição dos municípios por áreas englobadas pelas Secretarias de Educação. Estado do Rio de Janeiro - 2000

Fonte: Pesquisa Formação de profissionais da educação infantil no Estado do Rio de Janeiro: concepções, políticas e modos de implementação. Microdados. Rio de Janeiro: PUC-Rio, 2000.

Assim, 65\% das Secretarias Municipais de Educação assumem as funções da cultura e/ou esporte, lazer e turismo, entre outras, o que, com certeza, cria um ethos institucional diferente daquelas que só assumem a educação. A identidade da secretaria é construída a partir da sua meta, das diretrizes de sua criação e, no caso da educação, do compromisso com a escola, da formação dos profissionais, do espaço físico, mobiliário, material de consumo, condições do prédio, proporção adulto-criança, proposta pedagógica, enfim, da criação de um clima escolar referente à sua função. O ato de compartilhar entre secretarias, quando há uma política clara e bem definida sobre o atendimento educacional, os deveres das instituições regulamentação do atendimento e formação de professores - e os direitos das crianças aprimora o processo.

Entretanto, quando essa política não está definida ou está ainda em construção, vários são os problemas. Percebemos que as Secretarias de Educação que compartilham outras pastas estão localizadas nas regiões mais distantes dos grandes centros urbanos. Porém, municípios como Itaperuna, Porciúncula, Varre-Sai e Laje do Muriaé fogem a essa regra.

O organograma das Secretarias Municipais de Educação, solicitado pela pesquisa a essas instâncias a fim de obter mais informações sobre as diferentes formas de organização, dá a dimensão dos diversos setores, as áreas de atuação e seus níveis hierárquicos. Apenas 29 secretarias anexaram o organograma, o que suscita algumas questões: a estrutura das secretarias é flexível? Apresenta diferentes contornos (competência e responsabilidade da equipe) de acordo com a realidade encontrada, distanciando-se do previsto no organograma? Estas secretarias têm um 
"organograma prático", mas não enquanto representação gráfica da estrutura? A falta de organograma seria falta de organização ou flexibilidade da estrutura?

A variedade de organização das secretarias, identificada na análise dos organogramas, se reflete também no acompanhamento pedagógico às escolas: 52 secretarias responderam que têm equipe de profissionais envolvidos nessa atividade, e 2 secretarias responderam que não têm equipe (Miguel Pereira, na Região Centro-Sul, e Itaocara, na Região Noroeste). Neste caso, cabe perguntar se não têm realmente equipe ou se não fazem o acompanhamento. Isto porque podem não ter uma equipe específica para supervisionar pedagogicamente as escolas, mas o acompanhamento pode ser realizado por outros técnicos de funções diferenciadas.

Das secretarias que afirmaram ter setor específico de educação infantil, 93,9\% têm profissionais específicos para tal setor, 84,8\% têm profissionais que acompanham e orientam a educação infantil e, em 57,6\% dos municípios, o plano de carreira para os profissionais foi elaborado. Tal fato, a princípio, aponta para uma valorização do atendimento de educação infantil, nas redes municipais. A situação das creches é ainda obscura, visto que esse atendimento, em muitas localidades, é feito pela Secretaria de Assistência/Desenvolvimento Social, conforme apontam os questionários.

Todos os que têm equipe para acompanhamento pedagógico afirmam orientarem estabelecimentos de educação infantil. Não foi possível observar no organograma, tampouco nas respostas a esses quesitos sobre o sistema de ensino, o lugar das creches e pré-escolas privadas nas Secretarias de Educação. A não referência às atividades de orientação, credenciamento, supervisão e fiscalização por todos os municípios nos faz supor a falta de articulação das redes pública e privada no sistema de educação, ou melhor, a provável existência de uma política diferenciada para creches e pré-escolas públicas e privadas.

Em artigo sobre a regulamentação da educação infantil, Campos (1998, p. 46) - baseada nas preocupações de Gwen Morgan sobre o processo de regulação da oferta e do atendimento educacional - afirma a importância de haver padrões mínimos de qualidade na concessão de autorização para o funcionamento das instituições, a favor do interesse público e da proteção das crianças e famílias, minimizando a defesa de interesses corporativos dos profissionais e evitando parecer que os estabelecimentos já existentes estão sendo beneficiados pelo controle do aumento da concorrência.

Quanto ao número de profissionais que compunham a equipe de acompanhamento, é enorme a dispersão: mínimo um e máximo 155 técnicos. Essa diferença era esperada, se considerarmos o tamanho e a diversidade dos municípios do Estado do Rio de Janeiro.

Certamente, todas as secretarias atuam na área pedagógica. Vale indagar qual o seu compromisso com as escolas da sua competência (rede pública e rede privada), já que o município é um ente federativo autônomo e tem titularidade para assumir a rede de ensino. 


\section{A educação infantil}

Neste item apresentamos a cobertura do atendimento, a organização do ensino fundamental e da educação infantil nas Secretarias Municipais de Educação do Estado do Rio de Janeiro. De posse dos dados, buscamos traçar um panorama da cobertura do atendimento da educação básica e da educação infantil, para compreender a realidade do atendimento, a concepção de educação e os modos de implementação das políticas para a infância.

\subsection{Cobertura do atendimento}

A partir da constatação de que a maioria dos municípios já possui sistema próprio de ensino e, por isso, já gozam de plena autonomia para organizar e gerir a educação de acordo com as especificidades municipais, procuramos conhecer a realidade educacional, cobertura do atendimento, dos municípios do Estado do Rio de Janeiro.

Dos 54 municípios que responderam ao questionário, apenas 21 (38,9\%) informaram sobre o número de crianças de 0 a 6 residentes no município, sendo que, desses, em apenas 6 (Campos, Italva, Quissamã, Rio Claro, Sumidouro, Volta Redonda) o número se aproxima da estimativa do IBGE (menos de 10\% de diferença); os demais subdimensionam o número de crianças residentes. Fica evidente que a maioria dos municípios não conhece a sua população infantil de 0 a 6 anos de idade, desconhecimento que tem implicações para o traçado de políticas municipais para a educação infantil. A elaboração de metas para um Plano Municipal de Educação, como prevêem a LDB e o Plano Nacional de Educação, está, evidentemente, condicionada ao conhecimento do número das crianças residentes naquele município, por faixa etária, a fim de que se estabeleçam previsões de cobertura, segundo as diferentes idades.

Quanto ao total de crianças matriculadas na educação infantil, qualquer comparação entre os dados fornecidos pelo Censo Escolar e os dos municípios seria precipitada. Observando os dados, percebe-se que os municípios usaram critérios diferentes dos do Censo Escolar para contabilizar o número de matrículas. Dos 48 municípios que informaram esse dado, em apenas 10 (Armação de Búzios, Arraial do Cabo, Cantagalo, Guapimirim, Macaé, Piraí, Porciúncula, Porto Real, Saquarema, Silva Jardim) os dados se aproximam, 29 apresentam números de matrículas inferiores aos do Censo Escolar (pré-escola e CA) e 9 (Areal, Carapebus, Cardoso Moreira, Iguaba Grande, Italva, Paracambi, Quissamã, Santa Maria Madalena e Varre-Sai) apresentam números mais elevados.

A não compatibilização entre os dados do Censo Escolar e os fornecidos pelos municípios pode ser analisada, em alguns casos, como o desencontro do ano vigente - com que lidam algumas secretarias - e o ano anterior, com que trabalha o Censo.

Outra questão relevante diz respeito ao que os municípios consideram como creche e pré-escola. A nomenclatura encontrada em resposta ao questionário é bastante difusa: 1) creche, muitas vezes, é um local que atende a crianças em horário integral, não importando a idade; 2) pré-escola pode 
ter crianças de menos de quatro anos matriculadas, desde que em horário parcial; 3) as crianças de 6 anos ora fazem parte da pré-escola, da educação infantil, ora do ensino fundamental; 4) as crianças com dificuldades e/ou necessidades especiais são alocadas na pré-escola, independentemente da sua idade, etc.

Dessa maneira, a informação dos municípios sobre as matrículas na préescola segue, também, critérios diversos. Nas somas totais enviadas à pesquisa, os municípios podem ter incluído crianças das creches (0 a 3 anos), podem ter deixado de contar as crianças da faixa etária de pré-escola que freqüentam espaços denominados de creches, podem não ter incluído crianças das outras redes de ensino, alguns podem ter contado as crianças de 6 anos na pré-escola, outros no CA e outros ainda no ensino fundamental. Enfim, estamos diante de um enredamento de questões que apenas revela o quanto as informações são difusas e dispersas nas Secretarias Municipais de Educação, que, embora sejam responsáveis por enviá-las ao MEC/Inep, desconhecem-nas ou as desconsideram, tomando outras como referência.

Dos dados levantados, vale destacar o baixo índice de atendimento na Região Metropolitana do Rio de Janeiro. Indagamos: quem tem sido responsável pelo atendimento das crianças residentes nesses municípios? Com certeza, existe um atendimento "oficioso" que os sistemas municipais de ensino não levam em consideração, senão haveria um contingente ainda maior de crianças na rua.

\begin{abstract}
A Baixada Fluminense é um retrato em branco e preto do Brasil. Situase próximo à cidade do Rio de Janeiro e faz parte da área metropolitana. Começando pelo povo da Baixada: $60 \%$ a $70 \%$ da população é de raça negra. Esse povo descende da situação criminosa e vergonhosa que foi a escravatura no Brasil. A maioria ainda vive hoje uma escravidão de fato, que é a marginalização, a impossibilidade de participar de verdade da vida social, econômica e política do país. A Baixada é também o espaço dos migrantes, expulsos da terra. São os irmãos brasileiros que foram escorraçados do Nordeste e de outras regiões do país, que vêm buscar um espaço de vida. E aqui sofrem novamente. Sem esse povo "a cidade maravilhosa" não se explica, não se mantém de pé, não vive. É nesse contexto de Brasil injusto que nós devemos compreender a Baixada Fluminense e sua população (Dom Mauro Morelli, bispo da Diocese de Duque de Caxias e São João de Meriti).
\end{abstract}

Este triste depoimento elucida a situação em que vive a população residente nesta área do Estado; nos faz supor que a proliferação de creches, das chamadas "escolinhas de fundo de quintal" ou de iniciativas como mães-crecheiras, entre outras, é responsável pelo atendimento das crianças. Segundo Kappel (2000, p.135),

\footnotetext{
As estatísticas educacionais sobre o atendimento a crianças de 0 a 6 anos de idade, obtidas a partir do Censo Escolar, apresentam precariedades, pois existe um número significativo de creches e pré-escolas que funcionam sem qualquer registro e estas não são incluídas nos levantamentos oficiais do MEC. Já as pesquisas domiciliares do IBGE garantem, em seus levantamentos, além da freqüência escolar das crianças em instituições cadastradas, a dos alunos em instituições não cadastradas (filantrópicas, comunitárias, etc.).
} 
A autora chama a atenção para o fato de que, em todas as idades, os dados sobre freqüência escolar da Pnad-IBGE (Pesquisa Nacional por Amostra de Domicílios) são maiores dos que os do Censo Escolar. Porém, considerando a faixa etária de 0 a 6 anos de idade, essa diferença chega a 26,3\%, correspondendo a mais de um milhão de crianças, em todo território nacional, que freqüentam instituições desconhecidas pelos órgãos oficiais.

A iniciativa recente do MEC e o empenho de diferentes fóruns estaduais de educação infantil em torno do Censo da Educação Infantil têm sido fundamentais para o conhecimento mais próximo da realidade do atendimento das crianças de 0 a 6 anos de idade, mas ainda é preciso mobilizar creches e entidades afins para se fazerem presentes nos levantamentos estatísticos, o que não é tão simples, uma vez que muitas delas são improvisadas, apresentando instalações precárias, falta de pessoal especializado e/ou em situação trabalhista legal, etc. A "ilegalidade" de diferentes instituições de atendimento à infância se produz no vácuo deixado pelo poder público, tanto por sua omissão na oferta de vagas para essa faixa etária (0 a 3 é quase inexistente) quanto pela dificuldade de integrar esses estabelecimentos ao sistema de ensino, isso porque falar de integração é nomear responsabilidades e competências produzidas em torno de uma política educacional. De acordo com a LDB, Estados e municípios autorizam, credenciam e supervisionam os estabelecimentos de seus respectivos sistemas de ensino, que, segundo as diretrizes operacionais de educação infantil, são compreendidos por

[...] instituições escolares responsáveis pela oferta da educação escolar dentro de níveis e etapas discriminadas, com normas educacionais que, isentas de antinomias, dêem organicidade e unidade ao conjunto sob o influxo dos princípios, finalidades, valores e deveres da educação postos pela Constituição e na LDB e sob o competente órgão executivo (CNE, Câmara de Educação Básica, Parecer no 4, de 16/2/2000).

\subsection{Organização do ensino fundamental}

Outro aspecto que permite uma análise da situação da educação nos municípios se refere à organização do ensino fundamental. Perguntamos como está organizado o ensino fundamental no município: (I) em séries, quantas e quais são; (II) em ciclos, quantos e como se caracterizam. Vale lembrar o movimento, desde a LDB de 1996, de ampliação do ensino fundamental obrigatório de nove anos de duração, a iniciar-se aos seis anos de idade. Tal movimento, tornou-se meta da educação nacional pela Lei $\mathrm{n}^{\circ}$ 10.172/2001, que aprovou o Plano Nacional de Educação e se consubstancia em lei em 6 de fevereiro de 2006 (Lei no 11.274). Os dados coletados pela pesquisa, em 2000, refletem um momento de transição e contribuem por dimensionar os problemas desta inserção. Dos 54 municípios que responderam ao questionário, 43 (79,6\%) têm o ensino fundamental organizado em séries e, desses, 39,5\% informaram que as séries são compostas pelas turmas do CA à $8^{\mathrm{a}}$ série. O número médio de séries foi sete, quando o 
ensino fundamental deve ter, no mínimo, oito séries. Isso pode ser explicado porque 28 municípios (51,8\% dos casos) têm esse nível de ensino organizado em ciclos, dos quais 14 se organizam, também, em séries, quais sejam: Areal, Duque de Caxias, Casimiro de Abreu, Italva, Japeri, Miguel Pereira, Natividade, Piraí, Porciúncula, Quissamã, Rio das Ostras, Rio Claro, Rio de Janeiro, Sumidouro, Varre-Sai, Volta Redonda.

A questão dos ciclos (quantos e quais) foi das mais complexas de serem codificadas. Os questionários respondidos apresentaram uma grande diversidade de possibilidades de organização: 6 municípios não souberam responder a forma de organização dos ciclos; 6 municípios entenderam ciclo como segmento (primeiro segmento $-1^{\mathrm{a}}$ a $4^{\mathrm{a}}$ série $-\mathrm{e}$ segundo segmento $-5^{\mathrm{a}}$ a $8^{\mathrm{a}}$ série do ensino fundamental); 9 municípios o fazem agrupando séries $\left(1^{\circ}\right.$ ciclo - CA e $1^{\mathrm{a}}$ série; $1^{\mathrm{o}}$ ciclo - CA, $1^{\mathrm{a}}$ e $2^{\mathrm{a}}$ séries; $1^{\mathrm{o}}$ ciclo $-1^{\mathrm{a}}$ e $2^{\mathrm{a}}$ séries; $2^{\mathrm{o}}$ ciclo $-3^{\mathrm{a}}$ e $4^{\mathrm{a}}$ séries; $3^{\mathrm{o}}$ ciclo $-5^{\mathrm{a}}$ e $6^{\mathrm{a}}$ séries; $4^{\mathrm{o}}$ ciclo $-7^{\mathrm{a}}$ e $8^{\mathrm{a}}$ séries). Vale ainda ressaltar que 7 municípios adotam outros critérios de organização em ciclos, não sendo possível agrupá-los nas categorias acima.

A pergunta que cabe fazer é: diante de tal pluralidade e das rápidas transformações por que passam as organizações do ensino fundamental, como o processo de formação continuada dos professores vem subsidiando teórica e metodologicamente os profissionais da área? Para incrementar este diálogo, foi também perguntado aos municípios com que idade as crianças ingressam no ensino fundamental e se há algum pré-requisito.

Dos respondentes, 48 municípios (88,9\%) disseram que a idade é de 6 anos. Apenas 6 municípios que responderam ao questionário mantêm a idade de 7 anos para o ingresso no ensino fundamental. Já se pode afirmar que essa mudança está mais diretamente relacionada com a questão do Fundef do que a opções pedagógicas, fato reforçado, inclusive, pelos prérequisitos para tal ingresso, independentemente da idade: 51,9\% informaram que havia pré-requisito e mais da metade apontou a idade de 6 anos como tal, sendo definida por $88,9 \%$ dos casos por portaria das Secretarias Municipais de Educação.

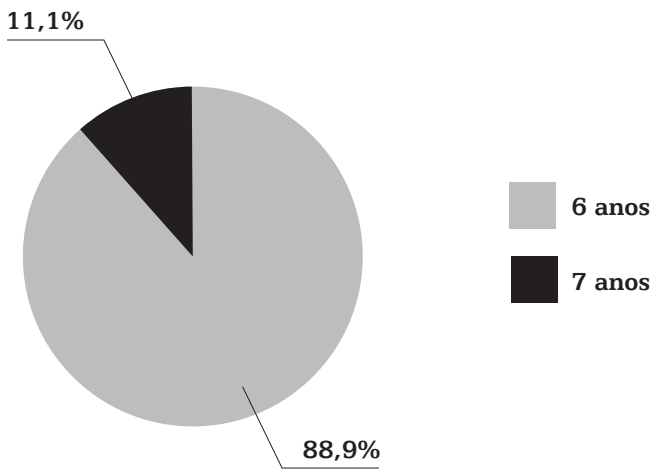

Gráfico 2 - Distribuição dos municípios por idade de ingresso no Ensino Fundamental. Estado do Rio de Janeiro - 2000

Fonte: Pesquisa Formação de profissionais da educação infantil no Estado do Rio de Janeiro: concepções, políticas e modos de implementação. Microdados. Rio de Janeiro: PUC-Rio, 2000. 
A questão das classes multisseriadas ficou também subjacente a duas perguntas que fizemos sobre existência de turmas de creche (0 a 3 anos) e de pré-escolas (4 a 6 anos) na área rural. Oito municípios disseram ter turmas de creches na área rural, mas apenas seis informaram a quantidade de turmas - sendo que o cálculo da média de turmas ficou prejudicado pelo alto desvio-padrão (mínimo de 1 turma e máximo de 62 turmas) - e 38 municípios (74,5\%) afirmaram ter turmas de pré-escolas na área rural, mas apenas 28 responderam quantas turmas, e também aqui houve uma grande diferença entre o mínimo de turmas (1) e o máximo (26). A falta de informações sobre o número de turmas, especialmente de pré-escola, e o alto porcentual de municípios que disseram ter pré-escolas na área rural nos fazem levantar algumas questões: os municípios que apresentam um alto porcentual de atendimento em pré-escolas são justamente os que têm área rural, mas as crianças de 4 a 6 anos, residentes na área rural desses municípios, estariam realmente freqüentando turmas de pré-escola ou estariam inseridas nas classes multisseriadas, junto com as crianças de 1a a 4a série? Caso a resposta seja positiva, como seria possível, para um só professor, trabalhar tal diversidade etária e de nível de escolaridade? Como esse professor estaria organizando o tempo e o espaço escolares para atender a todas as crianças? Qual seria a concepção de pré-escola na área rural? Como não elaboramos, para esse questionário, nenhuma questão sobre a existência ou não de classes multisseriadas nos municípios e não encontramos nos dados do Centro de Informações e Dados do Estado do Rio de Janeiro (Cide) referências sobre elas, ficam as perguntas como sugestões para novas investigações e pesquisas.

\subsection{Organização e funcionamento da educação infantil}

Esta parte do questionário teve como objetivo conhecer como as Secretarias Municipais de Educação estão organizadas para atender à educação infantil, já que ela deve fazer parte dos sistemas municipais de educação, tendo, portanto, sua autorização de funcionamento, credenciamento e supervisão sob a responsabilidade da educação.

Perguntados sobre se a secretaria possuía um setor específico responsável pela educação infantil, 33 (61,1\%) dos 54 municípios que devolveram o questionário responderam que sim; os outros 21 disseram que não. Como há educação infantil em todos os municípios, podemos supor que a gestão e a supervisão dessa etapa da educação básica devem ser feitas pela equipe que acompanha os outros níveis de ensino, provavelmente a do ensino fundamental, isso porque a equipe de acompanhamento pedagógico da secretaria orienta a educação infantil em 43 municípios (79,6\%). É importante ressaltar que, dos 54 questionários, apenas 44 respostas foram válidas neste quesito. Mesmo com omissões, o número de municípios que dizem fazer um acompanhamento pedagógico às creches e pré-escolas é alto. Cabe saber, por meio de outras estratégias metodológicas (entrevistas coletivas, estudo de casos), como é feito esse acompanhamento, ou seja, como 
as secretarias concebem o supervisor/coordenador, suas atribuições, funções, competências e qualificação, como esse trabalho pedagógico é acolhido pelos profissionais das creches e pré-escolas, que relações existem entre acompanhamento pedagógico, planejamento e formação em serviço, entre outras questões.

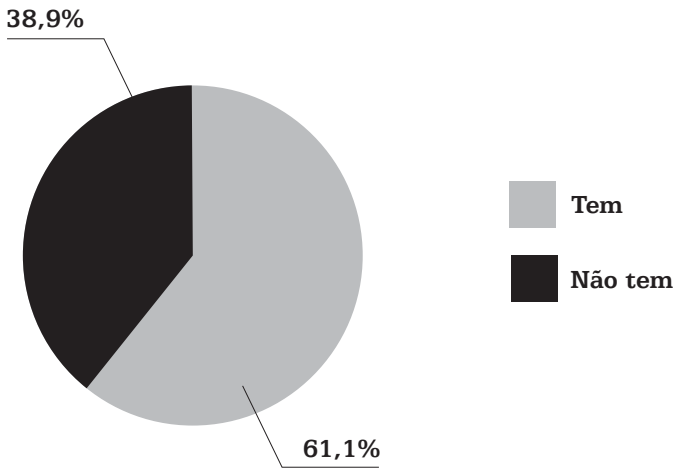

Gráfico 3 - Distribuição dos municípios por existência de um setor específico para educação infantil. Estado do Rio de Janeiro - 2000

Fonte: Pesquisa Formação de profissionais da educação infantil no Estado do Rio de Janeiro: concepções, políticas e modos de implementação. Microdados. Rio de Janeiro: PUC-Rio, 2000.

Perguntados sobre a freqüência do acompanhamento pedagógico aos estabelecimentos de educação infantil, a maioria dos municípios (25,9\%) informou que era semanal.

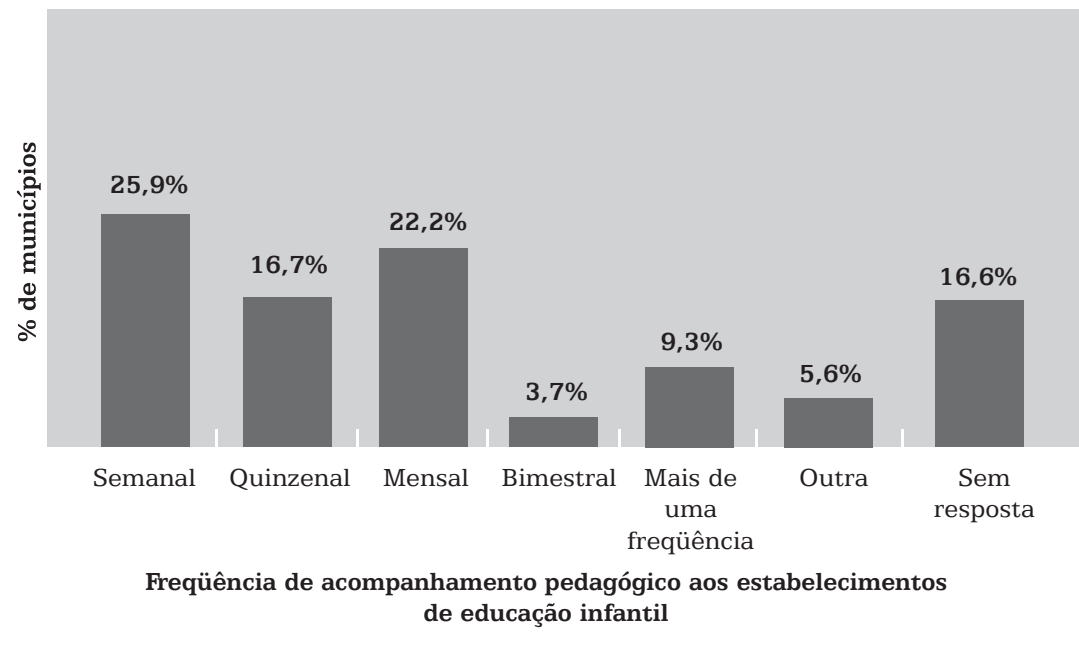

Gráfico 4 - Distribuição dos municípios por freqüência do acompanhamento pedagógico aos estabelecimentos de educação infantil. Estado do Rio de Janeiro - 2000

Fonte: Pesquisa Formação de profissionais da educação infantil no Estado do Rio de Janeiro: concepções, políticas e modos de implementação. Microdados. Rio de Janeiro: PUC-Rio, 2000 
Entretanto, a resposta a essa pergunta é ambígua: a freqüência assinalada se referia a que ponto de vista, do supervisor ou do estabelecimento? O acompanhamento feito semanalmente (ou o que segue outras freqüências) se refere à saída semanal do supervisor para visitar determinados estabelecimentos, ou cada creche e pré-escola recebe semanalmente um supervisor? Tomar um ou outro ponto de vista como resposta muda bastante o que pode ser considerado acompanhamento pedagógico, em especial quando se desconhece a relação entre o número de supervisores responsáveis pelo acompanhamento e o número de estabelecimentos.

Dos 46 municípios que responderam à questão sobre a existência de profissionais específicos para a educação infantil, nas secretarias, 37 (80,4\%) responderam ter esses profissionais na sua equipe de acompanhamento pedagógico;

mas quando perguntamos sobre o número deles, só 34 responderam e, como já era esperado pelas diferenças entre os municípios, o número mínimo foi de um profissional e o máximo de 18, o que deu uma grande dispersão para se calcular a média desses profissionais.

Desses 46 municípios, a maioria das Secretarias de Educação (43 municípios, 93,5\%) disse que os estabelecimentos de educação infantil possuem seus próprios coordenadores/supervisores. Esse porcentual é bastante significativo, mas, também aqui, o número isolado, sem considerar a qualificação e as condições de trabalho desse profissional, revela pouco sobre a qualidade do acompanhamento pedagógico realizado nas creches e préescolas do Estado do Rio de Janeiro. É preciso considerar, ainda, que 43 municípios correspondem a menos da metade do total de municípios do Estado e que quase 20\% das respostas foram negativas, ou seja, professores e auxiliares fazem o seu trabalho sem acompanhamento de perto, dependendo apenas das visitas dos representantes das secretarias.

Não perguntamos no questionário se as Secretarias de Educação supervisionavam os estabelecimentos das redes públicas (municipal, estadual e federal) e privadas (comunitárias, filantrópicas, confessionais e particulares) ou apenas as creches e pré-escolas municipais. Sabemos, por algumas entrevistas individuais e coletivas realizadas pela equipe de pesquisa, que o acompanhamento pedagógico das secretarias tem se limitado à rede municipal e, quando fazem algum tipo de acompanhamento às outras redes, fica restrito às questões de fiscalização administrativa ou sanitária. Esse acompanhamento ampliado e de cunho prioritariamente pedagógico é fruto de uma política efetiva de inserção da educação infantil à educação básica e da própria organização e gestão dos sistemas municipais de educação.

Quanto ao limite de vagas nas turmas de educação infantil, quase a metade $(43,4 \%)$ dos municípios que responderam ao questionário não atende crianças de um ano e os que atendem, em 30,2\% dos casos, colocam como limite de vagas entre 11 e 20 crianças por turma. As respostas mostraram que há uma ampliação desse limite à medida que as crianças vão atingindo idades mais avançadas. Assim, 26,4\% disseram que, para a faixa etária de 2 a 3 anos e 11 meses, o limite é de 16 a 20 crianças por turma; $54,7 \%$ disseram que, para a faixa etária de 4 a 5 anos e 11 meses, é de 21 
a 25 crianças; e 45,3\% informaram que, para as de 6 anos, o limite de vagas é também de 21 a 25 crianças por turma. A adequação ou não desses limites é de difícil discussão, uma vez que esse dado isolado não define a qualidade do atendimento. Outras informações sobre condições de trabalho nestes espaços não foram levantadas, mas podem e devem ser estudadas, tais como as características dos prédios, instalações e equipamentos, o projeto pedagógico e sua implementação. Tais aspectos são fundamentais para dimensionar se os limites estão ou não adequados para um trabalho educativo de qualidade nos espaços de educação infantil no Estado do Rio de Janeiro.

\section{Profissionais de educação infantil ${ }^{2}$}

Neste item apresentamos os dados referentes à formação mínima exigida para a atuação de professores e auxiliares, bem como os requisitos necessários para o desenvolvimento do plano da carreira docente nos municípios do Estado. No segundo momento, analisamos os mecanismos de nomeação dos diretores de creches e pré-escolas e os pré-requisitos exigidos para o ingresso e a carreira desses profissionais.

\subsection{Formação}

Chama atenção a diferença de formação mínima exigida para o exercício dos cargos de professor e auxiliar: 50 municípios que responderam ao questionário $(94,3 \%)$ exigem ensino médio para o professor, enquanto 22 municípios $(75,95 \%)$ disseram que ensino fundamental é requisito para ser auxiliar. São eles: Areal, Barra Mansa, Cabo Frio, Cardoso Moreira, Cordeiro, Duque de Caxias, Italva, Itaocara, Miguel Pereira, Miracema, Nilópolis, Paracambi, Paraíba do Sul, Quissamã, Rio Claro, Rio de Janeiro, Santa Maria Madalena, São Gonçalo, São João de Meriti, Silva Jardim, Tanguá e Varre-Sai.

Esses dados mostram a situação precária em que se encontra o auxiliar. Se a formação mínima é ensino fundamental, isso quer dizer que não têm formação específica de professor? Sua função é fazer faxina, limpeza, higiene das crianças, e não participam da formação pedagógica? E ainda, o alto número de informantes que não sabem ou não responderam à pergunta sobre formação mínima de auxiliares (25) indica que não há auxiliares nesses municípios? Ou sequer é exigido ensino fundamental para eles?

Esse tema revela o lugar que a educação infantil ocupa nas políticas municipais de educação: o da desvalorização, o do desprestígio e o da provisoriedade. Todo cidadão tem o direito à educação básica; nesse sentido, uma política que considera o direito à educação infantil não pode admitir um profissional que não concluiu a sua educação básica. O auxiliar, em muitos centros de educação infantil, desempenha, em última instância, um papel direto com as crianças, principalmente na pré-escola, onde o tempo com o cuidado é bem menor que o daquele dispensado aos bebês.

${ }^{2}$ Os dados apresentados neste item estão desenvolvidos em Corsino, Nunes e Kramer (2003). 
Quanto ao ingresso na rede, 40 municípios que responderam ao questionário (76,9\%) informaram que, em caso de concurso público, não existe prova específica para a educação infantil. A prova específica existe em 12 municípios; 2 municípios não sabem ou não responderam a este quesito. Duas são as considerações que podemos fazer diante deste dado: uma é de ordem pedagógica - não há exigência de nenhuma preparação específica prévia do professor para atuar com a criança pequena, nem como condição de entrada; a outra diz respeito à gestão - não havendo prova específica, os professores são selecionados como professores do ensino fundamental e, no Censo Escolar, constam como professores do ensino fundamental. Ora, como o Censo da educação infantil (MEC/2000) não obteve a informação de quantos professores atuam em creches, pré-escolas e turmas de educação infantil que funcionam em escolas de ensino fundamental, o dado continuará sendo impreciso e inútil, por não alimentar as políticas e não possibilitar ações, em especial, de formação.

Quanto à carreira, 27 municípios (50\%) informaram ter Plano de Carreira, o que significa que metade dos municípios respondentes não o possui.

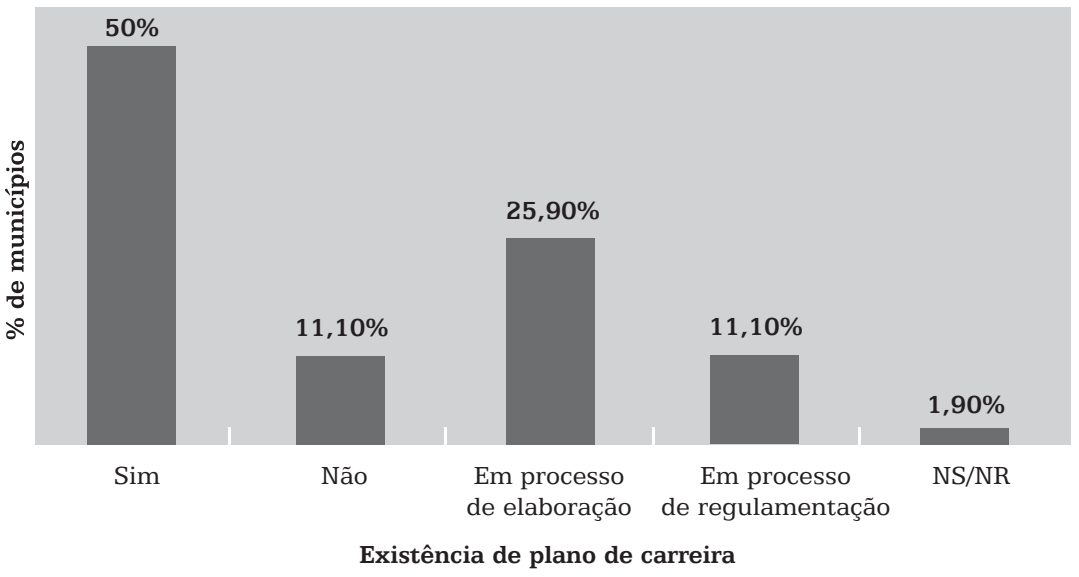

Gráfico 5 - Distribuição de municípios, segundo existência de plano de carreira. Estado do Rio de Janeiro - 2000

Fonte: Pesquisa Formação de profissionais da educação infantil no Estado do Rio de Janeiro: concepções, políticas e modos de implementação. Microdados. Rio de Janeiro: PUC-Rio, 2000.

No que diz respeito ao vínculo de trabalho dos profissionais que atuam na educação infantil, as respostas obtidas não permitiram saber o número de professores e auxiliares de cada município e seus respectivos vínculos empregatícios - estatutário, celetista, contrato temporário e outros -, isto porque houve falha no preenchimento do questionário, erro nosso na elaboração da pergunta e ambigüidade da própria situação dos vínculos existentes nos municípios. Mesmo assim, as informações obtidas mostraram que, na grande maioria dos municípios, 46, há professores estatutários. Em relação aos auxiliares, este número se reduz à metade, ou seja, 23 municípios afirmam ter 
auxiliares com o vínculo de estatutários. Fica evidente a existência de diferentes contratos de trabalho. Tal fato permite inferir que a educação infantil tem funcionado com professores com contrato provisório, o que pode desestimular investimentos de formação mais efetivos.

Um município diz exigir ensino fundamental para o professor, e dois municípios, estudos adicionais.

\subsection{Ingresso e carreira de diretores: mecanismos de nomeação e pré-requisitos exigidos}

Outro aspecto fundamental é o processo de nomeação de diretor de creches e pré-escolas. De acordo com os dados obtidos, parece que a nomeação ainda está bastante vinculada à indicação política, não havendo processos mais democráticos ou, pelo menos, transparentes, tais como eleição ou acesso por concurso: 40 municípios informaram que o mecanismo de nomeação do diretor é a indicação; a nomeação do diretor por eleição só existe em 11 municípios dos que devolveram o questionário, conforme podemos constatar no Gráfico 6.

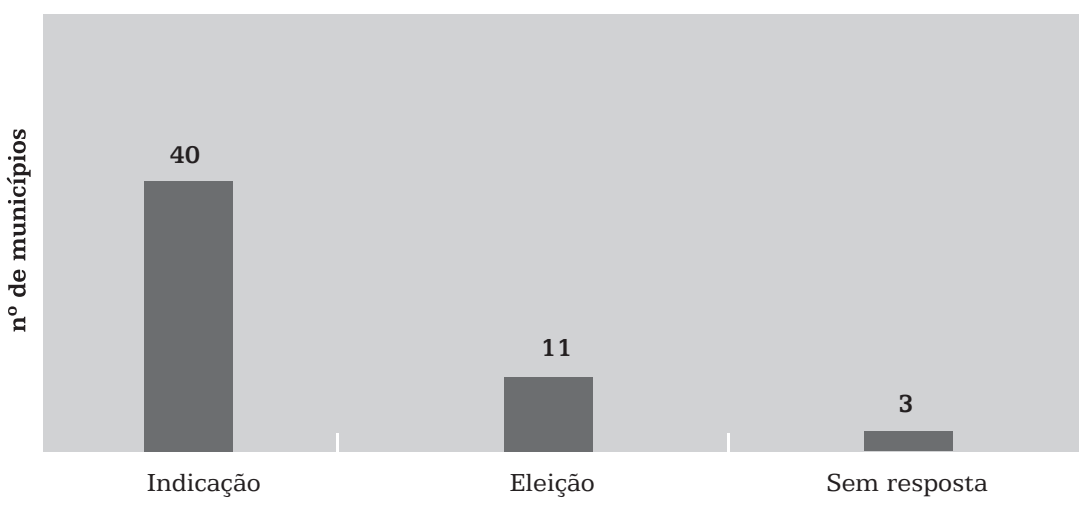

Gráfico 6 - Municípios por mecanismo de nomeação do diretor de creches e pré-escolas. Estado do Rio de Janeiro - 2000

Fonte: Pesquisa Formação de profissionais da educação infantil no Estado do Rio de Janeiro: concepções, políticas e modos de implementação. Microdados. Rio de Janeiro: PUC-Rio, 2000

Isso pode transformar o cargo de diretor, mais do que espaço de gestão escolar, em instrumento e espaço político. Essa questão foi mencionada nas entrevistas coletivas, onde entrevistadas explicitaram a entrada e interferência de políticos (vereadores) na escola, inclusive determinando a presença, na rede, de professores que não trabalham. Ainda nas entrevistas coletivas, esse problema foi relacionado com a conjuntura política mais ampla dos municípios. Tal aspecto será aprofundado no tópico referente à gestão da educação infantil. 
Quanto à direção, 36 municípios (66,7\%) informaram que existem requisitos mínimos para o exercício da função de diretor de creches e préescolas: destes, 14 indicaram o nível de escolaridade, 11 indicaram o nível de escolaridade e também a experiência profissional, 6 levam em consideração apenas a experiência profissional e 5 indicam características comportamentais e pessoais. Entretanto, 15 municípios alegam não terem nenhum requisito, o que reforça que este cargo é, muitas vezes, ocupado por indicação político-partidária, explicando, em parte, a falta de envolvimento do diretor no processo de formação em serviço.

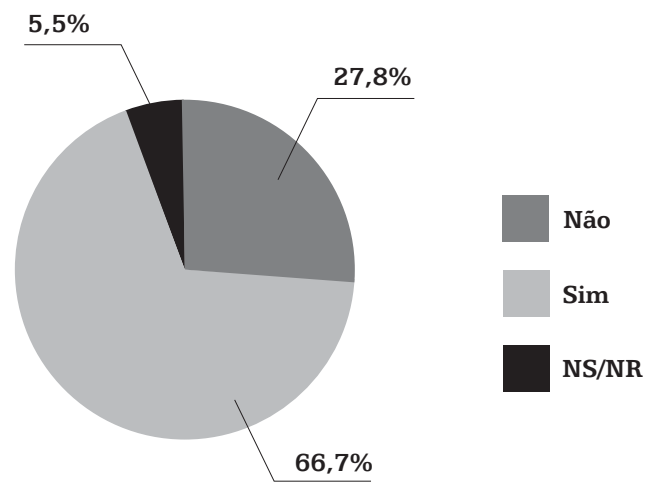

Gráfico 7 - Distribuição de municípios por existência de requisitos mínimos para diretor. Estado do Rio de Janeiro - 2000

Fonte: Pesquisa Formação de profissionais da educação infantil no Estado do Rio de Janeiro: concepções, políticas e modos de implementação. Microdados. Rio de Janeiro: PUC-Rio, 2000.

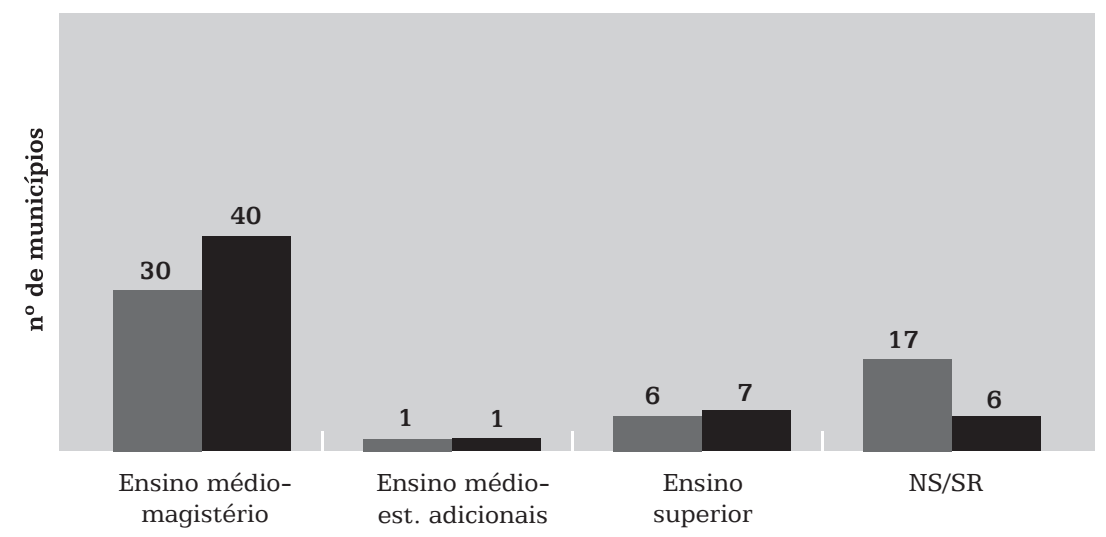

Formação mínima exigida para diretor de creches e de pré-escolas

Diretor de Creches

Diretor de pré-escolas

Gráfico 8 - Municípios por formação mínima exigida para o cargo de diretor de creches e de pré-escolas. Estado do Rio de Janeiro - 2000

Fonte: Pesquisa Formação de profissionais da educação infantil no Estado do Rio de Janeiro: concepções, políticas e modos de implementação. Microdados. Rio de Janeiro: PUC-Rio, 2000. 
Em relação à formação mínima exigida para ser diretor na educação infantil, tanto para os de creche quanto para os de pré-escola, há o predomínio da exigência do ensino médio-magistério, cerca de 80\%, e a exigência do ensino superior não chega a 10\% das respostas. Nesse contexto, em que estudos adicionais (apenas um município) e nível superior são pouco representativos, estando o peso colocado ainda no ensino médio, indagamos: como implementar educação infantil de qualidade sem projeto de formação que possibilite avanço na escolaridade dos profissionais envolvidos, conforme a determinação legal? As respostas analisadas a seguir permitem vislumbrar o quanto a formação em serviço ainda é um ponto frágil nas políticas municipais.

\section{Condições para a gestão: recursos materiais e agências culturais}

Conhecer os modos em que as práticas culturais alicerçam o trabalho de uma gestão municipal é entender o papel dessas práticas na formação de adultos e crianças. Neste item apresentamos dados sobre parcerias privilegiadas pela gestão municipal, instituições existentes nos municípios e a articulação destas com os projetos da secretaria de educação.

\subsection{Convênios com organismos não-governamentais}

Quando perguntados sobre a existência de convênios com creches que não pertencem à rede municipal de ensino e sobre qual a forma de apoio dada (questão 59), 14 municípios responderam afirmativamente e 13 especificaram a forma de apoio. São os seguintes os municípios que mantêm creches conveniadas: Angra dos Reis, Barra Mansa, Belford Roxo, Campos dos Goytacazes, Conceição de Macabu, Duque de Caxias, Itaperuna, Macaé, Niterói, Rio Bonito, Rio de Janeiro, Santo Antônio de Pádua, São João de Meriti e Volta Redonda.

Seria importante levantar os critérios que levaram a esfera municipal a realizar convênios com diversas instituições, principalmente quando se constata que, em todos os casos, as creches conveniadas são em maior número que as creches públicas. Forma de baratear custos? Não assumir obrigações trabalhistas? Não ter que realizar cursos de formação? Este é um tema polêmico, que merece destaque e deve ser aprofundado, em cada caso, por pesquisadores interessados pela área.

Dos municípios que mantêm convênio, 11 citaram a cessão de professores como forma de apoio, entre outras modalidades. Por outro lado, 8 municípios $(15,7 \%)$ disseram que existem outras secretarias que mantêm creches conveniadas (Belford Roxo, Campos dos Goytacazes, Conceição de Macabu, Duque de Caxias, Itaperuna, Rio de Janeiro, Rio Bonito e São Gonçalo), 7 citaram secretarias e/ou unidades da prefeitura ligadas à assistência ou ao desenvolvimento, 1 mencionou Secretaria do Trabalho e 1 município não respondeu qual. Nenhum município citou secretarias e/ou unidades da prefeitura ligadas à saúde ou agricultura. 
Já no que diz respeito à existência de convênios com pré-escolas que não pertencem à rede municipal de ensino e à forma de apoio dado, 4 municípios (8,2\%) informaram ter convênio com pré-escola e, destes, 3 fazem cessão de professores: Duque de Caxias, Itaocara e Santo Antônio de Pádua.

Por outro lado, 4 municípios afirmaram a existência de outras secretarias no município que mantêm pré-escolas conveniadas: 3 municípios informaram que se trata da Secretaria de Assistência e/ou Promoção Social e 1 município não soube dizer qual.

Como vimos, a inserção das creches e pré-escolas no sistema educacional é um dos pontos mais frágeis das políticas municipais para a educação infantil. Sem recursos próprios e sem recursos externos, as chances de implementação de políticas públicas de educação infantil se tornam ainda mais remotas. O Fundo de Manutenção e Desenvolvimento da Educação Básica (Fundeb) se coloca, nesse sentido, como essencial.

\subsection{Instituições/agências culturais ou sociais e as Secretarias Municipais de Educação}

Os dados sobre as instituições e agências culturais e sociais poderiam ter sido obtidos por meio de outras fontes, independentes deste questionário. Porém, foi nosso objetivo reforçar a importância do vínculo destas instituições com as políticas de educação dos municípios, de formação dos profissionais e das crianças. Ao responder ao questionário, o responsável pela educação infantil teria a oportunidade de dimensionar os recursos existentes no município e, também, a articulação destes com os projetos da secretaria de educação.

Dos 54 municípios que preencheram questionário, 47 (87\%) disseram que têm Biblioteca, 19 (35,2\%) disseram que têm livraria. Quanto a este aspecto, estudos específicos precisam ser realizados para conhecer o tipo de instituição que é considerada como biblioteca (biblioteca municipal, regional, biblioteca escolar, sala de leitura etc.), as condições de funcionamento, de atualização de acervo, de conservação dos livros, disponibilidade e formação dos funcionários, além da existência de acervo de livros infantis e os livros destinados a professores.

Além disso, estudos locais podem ajudar a compreender o que está sendo considerado como livraria: como já mencionamos, nas cidades de pequeno ou médio porte, é comum a existência de papelarias chamadas de livrarias, mas que vendem livros e materiais escolares exclusivamente didáticos.

Ainda segundo os questionários respondidos, há: clubes ou associações em 44 municípios (81,5\%); centros culturais em 31 (57,4\%); teatros em 17 (31,5\%), mais do que cinemas presentes em $13(24,1 \%)$ e museus em 12 (22,2\%); 8 municípios (14,8\%) disseram que possuem Sesc; 9 (16,6\%) que possuem Sesi; 16 (29,6\%) que existem outras instituições culturais. Os questionários não nos permitiram obter o número de cada uma destas instituições/agências culturais e sociais existentes em cada município. Eles estão disponíveis na Pesquisa Perfil dos Municípios 
Brasileiros: Pesquisa de Informações Básicas Municipais 1999, realizada pelo IBGE. Porém, a simples existência ou não delas fornece um pequeno panorama da circulação dos bens culturais pelo Estado do Rio de Janeiro. Chama atenção o número de municípios que não possuem museus, cinemas, teatros e centros culturais. Sabemos que a vida cultural de uma cidade não se limita a estas instituições formais. Há manifestações populares, extremamente ricas, espalhadas pelo Estado todo. Porém, o acesso à cultura no sentido amplo do termo engloba não só a valorização das manifestações locais, tão importante para a construção da identidade e valorização de cada município, como a ampliação para o que é e foi produzido nos diferentes lugares e épocas. $\mathrm{O}$ acesso aos bens culturais é um direito que não pode ser negado ou negligenciado. Este perfil dos municípios permite questionar: se a cidade do Rio de Janeiro se configura como um dos maiores centros culturais do Brasil, será que podemos dizer o mesmo da maioria dos outros municípios do Estado? Se os próprios municípios não oferecem opções culturais para os seus cidadãos, como romper com as diferenças tão marcadas entre os diferentes municípios do Estado? Foi possível notar que 44 Secretarias Municipais de Educação (81,5\%) desenvolvem atividades com as instituições culturais e sociais, número que consideramos significativo.

Assim, de acordo com os questionários respondidos, mais uma vez aparece a leitura como atividade cultural mais freqüente. Perguntamos: nestes municípios, estariam sendo desenvolvidas nas bibliotecas públicas atividades junto aos professores e alunos?

Tudo isso revela que o acesso aos bens culturais, para um grande número de profissionais da educação infantil, dos municípios do Estado do Rio de Janeiro, é ainda bastante restrito. O contexto cultural e científico em que a formação deles se dá tem ainda muitas lacunas, e a educação como parte de um projeto cultural mais amplo sofre restrições.

Chama atenção o número de municípios do Estado que não possuem museus, teatros, cinemas, centro culturais, bibliotecas, livrarias, etc., revelando que o acesso da população aos bens culturais, em muitos municípios, é desfavorável; portanto, o contexto cultural e científico em que se dá a formação dos profissionais de educação infantil tem lacunas, e a educação como parte de um projeto cultural mais amplo sofre restrições.

\section{Considerações finais}

Com base nessa pesquisa, concluímos que é urgente a implementação de políticas públicas de formação - direito de todos os profissionais -, de modo a assegurar condições dignas para práticas de trabalho com as crianças numa direção que reconheça sua condição de cidadãs. Tais políticas de formação precisam incluir diretrizes e estratégias de educação (prévia ou em serviço) dos profissionais, bem como formas de ingresso no sistema de ensino e planos de carreira que incorporem, nos salários, os níveis crescentes de escolaridade dos profissionais. É indefensável que o piso salarial de profissionais da educação seja definido pelo grau de escolaridade em que atuam. 
Educação infantil é direito de todas as crianças; formação é direito dos adultos. Com base neste direito, nossa recomendação é a de que sejam implementadas políticas municipais de educação infantil e de formação que, apropriando-se dos conhecimentos teóricos e firmando seu compromisso com as recentes conquistas constitucionais e legais, possam contribuir para diminuir o sofrimento de nossas populações infantis e possam assegurar o acesso de todos a uma educação infantil de qualidade, realizada em creches, pré-escolas e em escolas de ensino fundamental. Não é só da educação infantil que depende a justiça social, mas, para conquistar uma sociedade justa, combater a desigualdade social e econômica e reconhecer de fato a diversidade da nossa população, é preciso consolidar educação de crianças e de profissionais que com elas trabalham, brincam, atuam, interagem, convivem. Esperamos, com estas análises, contribuir para a elaboração de políticas públicas municipais e fornecer subsídios no sentido de cobrar do Estado do Rio de Janeiro e do governo federal a sua ação neste campo, tão marcado pelo descaso e falta de compromisso.

Aliando aos dados, que resultam de questionário e entrevistas aqui analisados, pesquisas realizadas anteriormente sobre leitura e escrita de professores (Kramer, 1996, 2001, 2005), concluímos sobre a urgência de formação cultural de professores, que tenham a leitura, a escrita e a literatura como eixos centrais. Precisamos assumir nossa responsabilidade diante dos fatos da vida cotidiana, da arte, do conhecimento científico, das políticas educacionais, sobretudo no que se refere à formação cultural de professores de educação infantil, considerados com sujeitos da sua prática que têm o direito à rememoração de suas histórias e à inserção crítica e criativa nas mais diversas instâncias e instituições sociais e culturais. Professores e professoras brasileiros que, convivendo com a violência, a pobreza, a exclusão, precisam ter a oportunidade não só de refletir criticamente sobre seu cotidiano com as crianças, mas também e principalmente de rever suas práticas concretas de inserção e de produção na e da cultura, repensando-se como sujeitos de seus atos éticos, como jovens e adultos, homens e mulheres, vinculados na tarefa coletiva que é a educação de crianças de 0 a 6 anos.

As mudanças se colocam urgentes diante da situação concreta e das práticas observadas e pesquisadas por muitos de nós em creches, escolas de educação infantil e de ensino fundamental. A aprovação final do Fundeb acentua o sentido de nossa responsabilidade. Sem ele, esta responsabilidade precisará - como sempre - da mobilização política que orientou nossas ações e nossa vida nestas décadas. Com o Fundeb, as práticas de gestão, de formação e atuação com as crianças precisam estar no centro da cena. Para que isso ocorra, a mobilização e a ação conjunta entre órgãos públicos, movimentos sociais e profissionais de educação infantil continuam a ser imprescindíveis, para que se logre enfrentar os desafios que estão hoje postos para a conquista da qualidade e para que nunca mais encontremos - nas instituições de educação infantil - a humilhação, 
o descaso, o abandono, os castigos, a tristeza, a desvalorização do conhecimento e da brincadeira, o despreparo dos adultos, o número excessivo de crianças, a discriminação, o preconceito, a falta de carinho, de curiosidade e de iniciativa de crianças e adultos, a falta de espaço, de natureza, de brinquedos e das mais variadas formas de expressão e criação artística e cultural que faz de nós, crianças e adultos de quaisquer idades, humanos.

\section{Referências bibliográficas}

BOTH, Ivo José. Municipalização da educação: uma contribuição para um novo paradigma da educação. Campinas: Papirus, 1997.

BRASIL. Constituição da República Federativa do Brasil. Brasília, 1988.

CAMPOS, Maria Malta. Educação infantil: o debate e a pesquisa. Cadernos de Pesquisa, São Paulo, n. 101, p. 113-127, jul. 1997.

CONSELHO NACIONAL DE EDUCAÇÃO. Parecer no 04, de 16 de fevereiro de 2000, institui Diretrizes Operacionais para a Educação Infantil. Disponível em: <http://www.mec.gov.br>

CORSINO, Patrícia; NUNES, Maria Fernanda; KRAMER, Sonia. Formação de profissionais de educação infantil: um desafio para as políticas municipais de educação face às exigências da nova LDB. In: SOUZA, Donaldo Bello; FARIA, Lia. Desafios da educação municipal. Rio de Janeiro: DPGA, 2003. p. 278-303.

INSTITUTO BRASILEIRO DE GEOGRAFIA E ESTATÍSTICA (IBGE). Disponível em: < http://www.ibge.gov.br>

KAPPEL, Maria Dolores. As crianças de 0 a 6 anos nas estatísticas nacionais. Rio de Janeiro: Ravil Editora, 2000. p. 120-150. Trabalho apresentado no Seminário Internacional da OMEP. Infância-Educação Infantil: reflexões para o início do século.

KRAMER, S. Formação de profissionais de educação infantil: questões e tensões. In: MACHADO, M. L. A. (Org.). Encontros e desencontros em educação infantil. São Paulo: Cortez, 2002. p. 117-132.

KRAMER, Sonia et al. Relatório da Pesquisa Formação de Profissionais da Educação Infantil no Estado do Rio de Janeiro. Rio de Janeiro: Ravil Editora, 2001.

KRAMER, Sonia (Org). Infância e educação infantil. Campinas: Papirus, 1999. 
KRAMER, Sonia. Profissionais de educação infantil: gestão e formação.

São Paulo: Ática, 2005.

MORELLI, Mauro. A Baixada para cima. [Brasília]: MEC/Fundação Educar/ Unicef, 1988.

NUNES, Maria Fernanda Rezende. Educação infantil no Estado do Rio de Janeiro: um estudo das estratégias municipais de atendimento. Tese (Doutorado em Educação) - Universidade Federal do Rio de Janeiro, 2005.

Sonia Kramer é professora do Departamento de Educação da Pontifícia Universidade Católica do Rio de Janeiro (PUC-Rio), onde coordena o curso de especialização em Educação Infantil.

sokramer@edu.puc-rio.br

Maria Fernanda Nunes é professora do Departamento de Educação da Pontifícia Universidade Católica do Rio de Janeiro (PUC-Rio) e pesquisadora da Universidade Federal do Estado do Rio de Janeiro (UniRio).

Recebido em 5 de outubro de 2006.

Aprovado em 8 de novembro de 2006 